\title{
Discourses of fact-checking in Swedish news media
}

\author{
Amalia Juneström \\ ALM, Uppsala Universitet, Uppsala, Sweden
}

\begin{abstract}
Purpose - The purpose of this paper is to examine how contemporary fact-checking is discursively constructed in Swedish news media; this serves to gain insight into how this practice is understood in society. Design/methodology/approach - A selection of texts on the topic of fact-checking published by two of Sweden's largest morning newspapers is analyzed through the lens of Fairclough's discourse theoretical framework.

Findings - Three key discourses of fact-checking were identified, each of which included multiple subdiscourses. First, a discourse that has been labeled as "the affirmative discourse," representing fact-checking as something positive, was identified. This discourse embraces ideas about fact-checking as something that, for example, strengthens democracy. Second, a contrasting discourse that has been labeled "the adverse discourse" was identified. This discourse represents fact-checking as something precarious that, for example, poses a risk to democracy. Third, a discourse labeled "the agency discourse" was identified. This discourse conveys ideas on whose responsibility it is to conduct fact-checking.

Originality/value - A better understanding of the discursive construction of fact-checking provides insights into social practices pertaining to it and the expectations of its role in contemporary society. The results are relevant for journalists and professionals who engage in fact-checking and for others who have a particular interest in fact-checking, e.g. librarians and educators engaged in media and information literacy projects.
\end{abstract}

Keywords Newspapers, Perception, Language, Communication, Attitudes, Information society

Paper type Research paper

\section{Introduction}

Contemporary fact-checking originates in the USA, where a number of well-known factchecking organizations, including FactCheck and PolitiFact, have been engaging in the practice for more than a decade. Brandtzaeg and Følstad (2017) divide fact-checking services into three main categories. The first includes fact-checking services concerned with political and public statements; the second includes organizations that aim to debunk online rumors; and the third includes fact-checkers that are concerned with particular issues, e.g. a specific political conflict. In Sweden, the best-known fact-checking project was Viralgranskaren, a division at the Metro newspaper, which went out of business in 2019. Viralgranskaren was set up in an attempt to verify or debunk rumors and news claims circulating on the Internet.

By analyzing a selection of texts published in two different major newspapers in Sweden, Dagens Nyheter (DN) and Svenska Dagbladet (SvD), this study aims to identify key discourses pertaining to fact-checking in Swedish news media and shed light on the ideological beliefs and values attached to fact-checking in contemporary society.

This aim can be translated into two specific research questions:

$R Q 1$. Which fact-checking discourses can be identified in the two newspapers?

(C) Amalia Juneström. Published by Emerald Publishing Limited. This article is published under the Creative Commons Attribution (CC BY 4.0) licence. Anyone may reproduce, distribute, translate and create derivative works of this article (for both commercial and non-commercial purposes), subject to full attribution to the original publication and authors. The full terms of this licence may be seen at http:// creativecommons.org/licences/by/4.0/legalcode

The author would like to thank her supervisors Professor Isto Huvila and Associate Professor Ulrika Kjellman at Uppsala University and Professor Jutta Haider at Borås University.

Received 17 March 2021 Revised 13 July 2021 Accepted 17 July 2021 


\section{Literature review}

The literature on fact-checking is closely tied to a growing body of research on disinformation, misinformation and other forms of misrepresentative messages that are communicated publicly, e.g. Iosifidis and Nicoli (2020) and Rubin (2019). There is a considerable, growing body of conceptual research on mis- and disinformation and related notions (e.g. Fallis, 2015; Søe, 2017, 2021), as well as on, for example, automatic recognition of false information. Other closely related topics of interest are those of news (Ireland, 2018; Tamboer et al., 2020), media (Jones-Jang et al., 2021; Stamps, 2020) and information (Gibson and Jacobson, 2018; Jacobson and Mackey, 2013) literacy. Although fact-checking, false information and literacy research are related topics, this study focuses explicitly on factchecking as a human practice rather than on what constitutes a fact, or mis- and disinformation.

While fact-checking is often understood as a genuinely journalistic practice, promoting the ability to determine whether a piece of information is reliable or not also engages other professional groups. Teaching information literacy has been embraced by librarians (Alexander and Wood, 2019; Gibson and Jacobson, 2018; Ireland, 2018; LaPierre and Kitzie, 2019) and educators (Alexander and Wood, 2019; Lorenz et al., 2019). Fact-checking does, however, differ from information and media literacy education. While fact-checking serves to verify the accuracy of a piece of information, information literacy aims to develop the ability to recognize whether it is trustworthy or not. Although the boundary between the scholarly fields taking an interest in the two topics is not always sharp, the topics themselves represent two fundamentally different approaches to tackling the experienced problem of false information: information literacy education aims at empowering individuals, while factchecking aims at helping them with the subject matter (Huvila, 2012).

In the following, the state of affairs regarding research on fact-checking will be discussed in relation to (1) its perceived benefits, (2) its drawbacks and (3) whose responsibility factchecking is understood to be.

\subsection{The benefits of fact-checking}

Fact-checking as a journalistic device to correct false statements and political disinformation has gained increasing popularity in the contemporary news media landscape (Amazeen, 2019, 2020; Graves, 2016; Marietta et al., 2015; Mena, 2019). It has, at least to a certain degree, been found to be effective in correcting misrepresentations (Amazeen, 2015; Benegal and Scruggs, 2018; Chan et al., 2017; Garrett et al., 2013). Scholarly literature also reflects ideas on fact-checking as a tool for finding truth when evaluating political information. It is understood as an instrument through which key journalistic principles can be supported (Graves et al., 2016) and with which traditional ideals of journalism such as objectivity, credibility and autonomy can be upheld (Amazeen, 2015; Damasceno and Patrício, 2020). In their field experiment, Graves et al. (2016) found that the growing popularity of fact-checking is largely a response to the way it "appeals to the professional values and status concerns of journalists" (Graves et al., 2016, p. 121). Along the same lines, fact-checking has been conceptualized as a democracy-enhancing device that benefits citizens and positively impacts their perceptions of truth in relation to political issues (York et al., 2020).

\subsection{The drawbacks of fact-checking}

Although the bulk of academic research on fact-checking views the practice and its ability to correct disinformation positively (Amazeen, 2019, 2020; Graves, 2016, 2018; Mena, 2019), 
some scholars have proposed that the impact of fact-checking is rather limited (Garrett et al., 2013; Nyhan and Reifler, 2014; Sanna et al., 2002). It has also been suggested that factchecking may have counterproductive effects when it comes to correcting misrepresentations and, instead of rectifying them, may make false beliefs harder to wipe out (Nyhan and Reifler, 2010; Sanna et al., 2002). As Niemen and Rapeli (2019) point out, articles examining what the general public thinks about fact-checking are not as frequent as those studying its corrective nature. However, in Brandtzaeg and Følstad's study (2017), social media users' negative attitude toward a fact-check is linked to their trust in the fact-checker behind it.

Scholars have also proposed that possible biases on the part of fact-checking organizations could obstruct the purpose of finding truth (Uscinski, 2015; Uscinski and Butler, 2013). Uscinski and Butler (2013) describe the epistemology of fact-checking journalism as naïve and argue that the practice is too inconsistent and flawed for citizens to rely on when looking for truth.

\subsection{The responsibility of fact-checking}

While many of the most prominent fact-checking organizations do not have journalistic roots, e.g. Snopes, many scholars recognize contemporary fact-checking as an essential part of a journalistic pursuit (Graves, 2016, 2018; Mena, 2019). Much of the research conducted on contemporary fact-checking is correspondingly conducted within media studies and journalism. Amazeen describes fact-checking as a "type of journalism" (Amazeen, 2015, p. 3), and Graves and Anderson (2020) do not make a clear distinction between journalists and fact-checkers as professional groups in their study "Discipline and promote," which refers to fact-checking as "a new genre of journalism" (Graves and Anderson, 2020, p. 344). Although professional motives are not considered to be the only reason for the expansion of factchecking, Graves et al. (2016) define fact-checking as "one of the most significant innovations in journalistic practice in recent years" (Graves et al., 2016, p. 106) and suggest that journalists understand their fact-checking work as a new type of reporting.

Although social media is often blamed for hostility and fraudulence in online discussions (Farkas and Schou, 2020), previous research on contemporary fact-checking has not been found to engage with fact-checking as a responsibility of social media providers. Although social media is, undeniably, an essential tool used by news media outlets (Brandtzaeg et al., 2018), the literature on the role that the major social media platforms play in relation to factchecking is still, to the author's knowledge, limited.

\section{Critical discourse analysis}

The main tenet of critical discourse analysis is that the language we speak and write determines what we think and how we act. We create meaning through language, and the representations of fact-checking that the newspapers examined in this study communicate are assumed to have the power to influence both public discourse and how fact-checking is practiced in society.

\subsection{Fairclough's critical discourse analysis}

This research draws on Fairclough's critical discourse theoretical framework (CDA), with a three-dimensional inquiry into communicative events being applied to the study of media texts from two major Swedish news sources. The three dimensions of Fairclough's analytical model are (1) the textual dimension, in which textual components such as words and sentences contribute to constructing a discourse; (2) the discourse practice dimension, in which the production, distribution and consumption processes of the texts are analyzed; and (3) the

Discourses of fact-checking 
JD

78,7

128

sociocultural practice dimension, in which the social implications of the discourses are studied (Fairclough, 2010).

In the study, special attention is paid to the first two dimensions of Fairclough's framework.

Language is studied in depth. Words, according to Fairclough, reproduce specific ideologies (Fairclough, 2010), and particular focus is directed toward the choice of words that are used to phrase ideas about fact-checking. Besides words, the analysis also pays attention to the discursive practices, that is, the processes through which the texts are created and consumed. In focus are the intertextualities of the texts.

The third and final dimension of analysis reflects upon the cultural consequences of the identified discourses. This final dimension opens up a potential contextualization of this study's findings in relation to earlier research on fact-checking and will be scrutinized in relation to earlier literature in the discussion section of the study.

\section{Method and material}

For this study, a corpus of texts was selected and downloaded from two Swedish national daily newspapers: Dagens Nyheter (DN) and Svenska Dagbladet (SvD). As the two largest national morning newspapers in Sweden, $\mathrm{DN}$ and SvD can be expected to provide a reasonably dependable insight into the mainstream Swedish public discourse on factchecking. The newspapers define themselves as an independent. However, DN positions itself politically as liberal and SvD as conservative, in terms of how liberal and conservative are understood in Swedish politics.

Before downloading any material from the two newspapers, keyword searches were conducted using the Swedish newspaper article database Svenska dagstidningar (SDT), provided by the Swedish Kungliga biblioteket [Royal Library], to identify for how long and where fact-checking has been discussed in the Swedish daily press. A search of the SDT verified that the occurrence of the term "faktagranskning," a noun that translates to "factchecking" in English, increased in 2013. The first time that the term was recorded was in 1967. In the following decades, the term rarely appeared more than a handful of times per year, if at all. In 2013, however, the term was used 13 times. There was then a sharp rise in the use of the term, culminating in 2018, when the word appeared 504 times. The verb "faktagranska" "to fact-check"] has a similar timeline. It does not appear quite as often and was first recorded in 1987, when it was used twice. After that, it did not appear more than four times in any one year until 2013. The terms "faktakoll" (noun) and "faktakolla" (verb), which would also translate to "fact-checking" in English, both showed similar patterns of development to the terms described above. "Faktakoll" peaked in 2018, when it appeared 343 times. The verb "faktakolla," the occurrence of which first spiked in 2014, also had the most hits in 2018, when it appeared 52 times.

On the basis of the SDT search results and a preliminary analysis of the topics covered by the retrieved articles, all the (quasi-)synonyms were left out of the search as their inclusion was not assessed as contributing significant added value. For the same reason, no truncation was used and, when collecting texts from the two newspapers, the keyword "faktagranskning" was searched for in both DN and SvD. The texts, which constitute the empirical data in this study, were located by using the search tools available in the two newspapers' own online archives.

Texts published between January 1, 2014, and December 15, 2020, were selected and downloaded from the search results of each newspaper's website, covering the period from the beginning of fact-checking's increase in popularity as a term up to the present. The texts represent different textual genres ranging from news and financial reports to opinion pieces and book reviews. 
All the texts in the search results underwent an initial review to remove texts with no apparent direct relevance to fact-checking. In practice, articles whose content did not relate to or discuss the practice of fact-checking were disregarded. For example, the article "Poland on its knees as Sweden attracts doctors" [author's translation] (SvD), reporting on the situation in Polish hospitals during the corona crisis, contained the word only in reference to a factchecking website cited in the article.

All the downloaded articles that were selected for an in-depth qualitative analysis were investigated through close reading, with 130 texts being retained for closer analysis. Of these texts, 66 were published in DN and 64 in SvD. The texts were analyzed using a method influenced by Fairclough's discourse analytical approach, with an emphasis on scrutinizing the linguistic features of the texts (Fairclough, 2010).

All the passages quoted below were translated from Swedish to English by the author. When translating text passages, there is always a risk that the intended meaning of the original is not accurately interpreted. However, the author has endeavored to communicate the message of the original texts faithfully while retaining their lexical and stylistic forms. Codes are used when referring to the articles that constitute the analyzed material. The articles are indexed using references made up of a code for the source newspaper (DN or SvD) and a number indicating each article's chronological position in the corpus of texts.

\section{Analysis}

The textual analysis identified a total of three key opposing and contradictory discourses. First, a discourse labeled as "the affirmative discourse" was identified. This discourse represents fact-checking as something positive that, for example, contributes to strengthening democracy. Second, the material also featured a contradictory discourse labeled here as "the adverse discourse." This discourse represents fact-checking as something precarious that, for example, poses a risk to democracy. Additionally, a third discourse was also identified and labeled "the agency discourse." Rather than focusing on the role of fact-checking, this discourse is constituted by ideas on the role of journalists, news media and social media in terms of their performance, or lack thereof, when it comes to conducting fact-checking properly. This discourse includes ideas on whose responsibility it is to fact-check. All the discourses are made up of multiple sub-discourses.

\subsection{The affirmative discourse}

Two sub-discourses were found to make up the affirmative discourse. First, fact-checking is understood to be a remedy for disinformation, which, in turn, is something that is often represented as a threat to democracy and society as a whole. Second, the texts often produce a positive picture of fact-checking as a tool for uncovering truth and securing objectivity. Both of these sub-discourses overlap with other discourses as well as with each other.

5.1.1 Fact-checking to remedy disinformation. Fact-checking is often discussed in the same context as disinformation, which is articulated as a social problem that needs to be combated.

The battle over information has become an ever-increasing part of security policy. By spreading disinformation, it is possible to create confusion and weaken the opponent (SvD3).

The discourse on fact-checking as a remedy for disinformation and the discourse on disinformation as a social problem often overlap. Usage of the term fact-checking peaked in the Swedish media in 2018. This was an election year in Sweden, and some of the major news media outlets, including DN and SvD, joined forces under the auspices of the collaborative fact-checking project Faktiskt [In fact]. In the following interview with SvD's fact-checking 
JD

78,7

reporter, the purpose of Faktiskt is discussed. Disinformation concerning the election is mentioned as a central reason for investing in fact-checking.

Do you believe that fake news may influence the election? - "Yes, I believe so. But it is probably not clear how much. In my emails from readers, I notice that some claims have spread widely, especially claims about immigration and criminality" (SvD22).

The interviewed journalist believed that disinformation was likely to unduly influence the election, and, therefore, the project he was going to be involved in during the months leading up to the election had a purpose to fulfill. Through being discussed as an antidote to disinformation, fact-checking unfolds as a remedy for its social impact.

5.1.2 Fact-checking to establish truth and objectivity. Fact-checking was found to be represented as a means of finding truth and achieving objectivity. An overlap between different discourses could be discerned. In this case, a discourse on the purpose of factchecking overlaps with one representing ideas about the relationship between journalism and truth.

The journalist's relationship to truth is in the news. The language of truth gives her the leading role as the author of the first draft of the history books. However, it also constitutes her critics' most important target [...] [i]n an inflated debate about fact-checking journalism, this has been one of the critics' central points: journalists should not be the ones to decide what is true or false (DN28).

In the headline "Editor-in-chief Zuckerberg fights to be excused from caring about truth" (DN13), truth and fact-checking are discursively represented as interlocking and intertwined. By calling Mark Zuckerberg an "Editor-in-Chief," the Facebook founder is portrayed in media terms, and in the article, which reports on Zuckerberg obstructing the introduction of new tools for increased fact-checking on Facebook, Zuckerberg's opposition to fact-checking is equated with an opposition to finding truth. Sometimes a discourse on fact-checking as a tool through which truth may be established overlaps with the understanding of fact-checking as a remedy for disinformation.

I was among those who not only thought that SVT's fact-check was excellent, but also necessary. [...] We cannot keep on sitting at the dining table and telling the kids to shut up because "here, we do not discuss whether the sun rises in the mornings." I will, if necessary, even take part in discussions on whether or not the Earth is flat - I will do everything in my power to fight lies (DN36).

This quote comes from a response to criticism directed toward Swedish television journalists who, as part of a fact-checking initiative, attempted to fact-check the claims of conspiracy theories that deny various components of the Holocaust took place, for example, the fact that Zyklon B was used to murder people in gas chambers. Taking the opposite view to the journalist making the criticism he is refuting, the author argues that every claim needs to be fact-checked, regardless of how stupid or offensive it may be. The purpose of finding truth, he argues, outranks everything else and, according to the quote, it is through fact-checking that this can be achieved. However, the quote also contains an understanding of fact-checking as a weapon with which to fight lies, i.e. disinformation may be remedied through the use of factchecking. The two sub-discourses thus overlap.

Objectivity is often represented as one of the core virtues of journalism (Mindich, 1998), and in this discourse, it is found to be interdiscursively connected with how the purpose of fact-checking is represented.

A fact-check is an objective check of a claim in the social debate. SvD is part of the Swedish factchecking collaboration Faktiskt and follows the guidelines of the international fact-checking organization IFCN (SvD21). 
This quote was included in a label at the top of every fact-check that SvD published as part of the Faktiskt project. Similarly, DN also provides information about its fact-checking work. In "This is how DN works with fact-checking" (DN39), the term "faktabaserad" ["based on facts"] is used as a synonym for objectivity in an article that states: "the purpose of the collaboration is to contribute to a public debate that is open, inclusive and based on facts” (SvD21).

\subsection{The adverse discourse}

The study found the adverse discourse to be composed of three sub-discourses. In the first, the effectiveness of fact-checking is contested. In the second, fact-checking is understood as a tool that can be used to impede democracy, e.g. to suppress freedom of speech, carry out censorship and assist political autocracy. In the final sub-discourse, fact-checking is understood as legitimizing conspiracy theories.

5.2.1 Fact-checking does not work. A reoccurring idea about fact-checking is that it is a rather toothless weapon against disinformation and fact resistance. It is claimed that, although the media and other social actors have invested heavily in fact-checking, disinformation is still being spread and misleading information is impacting public trust in, for example, policymaking and vaccination programs. Furthermore, an understanding of fact-checking as something that receives undue credit for remedying disinformation, despite its failure to deliver, was also found to be entwined with the discourse on fact-checking being an ineffective tool:

And although it proved pretty useless during the presidential campaign, there is a tendency, also among Swedish news media, to heroize fact-checking (DN16).

The above quote suggests an understanding of fact-checking as something that is unjustifiably promoted as a remedy for disinformation when it is actually a waste of time for journalists to try and convince the public what is true and what is not. However, ideas of this kind are contradicted by other texts in the empirical material.

"Fact-checking cannot save us," read the headline when Martin Schori put on his most pessimistic hat in Aftonbladet the other week. He lined up evidence of how fact-checking journalism fails to get across, does not make a difference, and thereby should not be the object of wasted resources (DN26).

In the above quote, a text's author repeats a claim made by someone who holds opposing opinions on fact-checking. A statement made in the Swedish evening newspaper Aftonbladet is used as an intertextual reference to emphasize the author's contrasting view. The author of the text from which this quote is taken does not share the view that fact-checking does not make a difference.

Conflicting discourses on the nature of journalism's core mission were found to play a role in the contradictory ideas on the effectiveness of fact-checking detailed above. Earlier, we saw that fact-checking is understood as a tool for finding truth, and finding truth, it is implied, is the core mission of journalists. However, if truth is not conceptualized as being what journalism is about in the first place, then fact-checking is not necessarily a key part of journalism either.

Traditional journalism has to relate to an ethical framework, and it has a completely different relationship to fact-checking and source criticism than those who spread hate. But does journalism really produce truth? I mean that it rather creates angled images of reality [...] (DN3).

These conflicting discourses do not just disagree on how fact-checking ought to be understood. At the bottom of how fact-checking is to be constructed discursively there are, as we have seen, conflicting ideas about the core purpose of journalism.

Discourses of fact-checking 
JD

78,7

5.2.2 Fact-checking can impede democracy. Although the view of fact-checking as a suppressant of freedom of speech was not found to be strongly advocated by the producers of the analyzed material, it is a common discourse that is present in the form of references to other sources. In the following quote, for example, the author uses the criticism of factchecking that he has found in other newspapers to highlight his own opposing view. The author describes the journalists, whom he quotes, as belonging to a group of right-wing debaters who disapprove of a media collaboration on fact-checking that involves several mainstream news organizations.

"Journalists are no inspectors of truth," writes Håkan Boström in Expressen. The key criticism is loud and clear: "The hunt for "fake news' is threatening to lead to online censorship" (DN27).

The text's author links the criticism made by the quoted journalist to similar views expressed by other journalists in Germany and France. He goes on to distance himself from viewing factchecking as a tool that can be used to exercise censorship. While acknowledging that there are reasons to be cautious about how fact-checking may be used, he accuses these voices of having a lack of insight into the topic they are debating. The above quote is another example of an author strengthening his own argument by citing opposing views. Unlike the journalists he criticizes, he asserts that the struggle to uphold freedom of speech and opinion is in fact the very force that motivates journalists to engage in fact-checking (DN27). However, the views of the reporter whose statements are quoted by the text's author do not just suggest an understanding of fact-checking as a tool that constitutes a form of censorship. They also reflect the same understanding of truth that was elaborated on in the previous sub-discourse.

The text quoted above is created through the use of another text. In fact, the abovementioned article contains two forms of intertextuality. First, we have specific quotes from other news articles. This kind of intertextuality is called manifest intertextuality, i.e. "the explicit presence of other texts in a text" (Fairclough, 1992, p. 10). We then have what Fairclough (1992) calls interdiscursivity, or constitutive intertextuality, i.e. the relationship that a discourse has to another discourse. In the text, the interdiscursivity is indicated by the author's partial acceptance of certain elements of the arguments made by the journalist he is criticizing; he recognizes that there are reasons to be careful about how fact-checking is used. It is clear that the text contains a power struggle between two conflicting views. Although the text's author does not share the understanding of fact-checking represented by the quoted author and other journalists, it is clear that he finds the idea important enough to debate.

The understanding of fact-checking as a tool with which to suppress freedom of speech and exercise censorship is not simply portrayed as incorrect in the analyzed material; it is also a discourse that is often represented as having obstructive powers.

Every time a right-wing populist is cut off from Twitter, Facebook, or YouTube after breaking the user regulations with extreme, racist, or offensive statements, the Republicans have cried out about freedom of speech being under threat [ . . . (DN58).

In the quote, the text's author argues that the discourse on fact-checking as something that impedes democracy can be used to spread inflammatory views. The idea of fact-checking as a tool to suppress freedom of speech was not often found to be expressed firsthand by the authors of the analyzed texts. More frequently, they expressed a view of fact-checking as a practice that risks serving autocratic purposes. This view is often conveyed as a word of warning about what might happen if fact-checking were to be unduly applied.

Also, one should be suspicious when democracies such as Germany and France legislate against "fake news" and hateful messages. Precisely because Emmanuel Macron sees himself as the defender of the good Europe, he should be careful which weapons he chooses for the defense. The risk of becoming the mirror image of one's enemy should always be part of the calculation (DN29). 
The above quote starts off with the recognition that fact-checking may be used to suppress democratic principles. It then goes on to construct a picture of how this tool may transform a leader with strong democratic aspirations into an autocrat. However, autocratic tendencies are not just ascribed to world leaders. The study found that the mainstream news media was often the target of a similar accusation relating to their use of fact-checking.

$[\ldots]$ the way this [fact-]checking association [Faktiskt] is being presented gives the impression that it is the elite media's common effort - i.e. one single voice that should say exactly what is true or false. That it is partly nationally funded undoubtedly contributes to the suspicion (SvD26).

In this opinion piece, the text's author expresses criticism of fact-checking in general and of the Faktiskt project in particular. Fact-checking is represented as something that unduly entitles the mainstream media to additional rights. According to this understanding, factchecking awards it the privilege of deciding what is true and what is not.

5.2.3 Fact-checking legitimizes conspiracy theories. One frequent argument against factchecking is that it gives unjustified credit to claims that are already officially and publicly recognized as fabrications. To fact-check obvious lies is not just considered to be dangerous but also immoral. By investing resources in fact-checking climate change denial or anti-Semitic claims about the Holocaust, it is argued that conspiracy theories are legitimized.

Therefore, the claim of the day is "the Holocaust is a lie," and further down it is ascertained that this is "in fact totally wrong." Red flag. That's alright, then! (DN35)

In this quote, journalists from Swedish television are criticized for having fact-checked false claims relating to the Holocaust, and the text's author uses irony to emphasize her standpoint of opposition to the conducted fact-check. When saying that it is alright to have debunked a Holocaust denial and awarded the claim the symbol of a red flag, the text's author in fact means that it is absolutely not alright. Irony, according to Fairclough (1992), works by way of echoing someone else's utterance. Of course, irony depends on the reader being able to understand that the meaning of the echo does not reflect the author's own view. In this case, reading the article in Swedish, the reader is left in no doubt about the echo's intended meaning. After acknowledging that the fact-checkers undoubtedly had the best intentions, the text's author goes on to accuse them of letting Nazi conspiracy theories set the agenda. Again, the text manifests a discoursal overlap. According to the reporter, the SVT fact-checkers have misunderstood their role in the contemporary media landscape.

Their [SVT's] function as an authority on truth is no more, and therefore the effect of "fact-checking" Nazi lies about the Holocaust achieves quite the opposite: It puts the issue on the agenda as something that can be questioned in public (DN35).

It is clear that there is an ideological conflict taking place between the opposing discourses. On the one hand, we have a discourse representing views of fact-checking as a tool prioritizing truth above all, and on the other, a discourse representing such efforts as obstructive.

The scientific support for initiatives such as Metro's Viralgranskaren, SVT's Faktakollen, and Faktiskt actually having any effect is weak. Unfortunately, the repetition of false information, which fact-checking involves, may even cement the effect of disinformation [... ] (SvD48).

Interestingly enough, the idea of fact-checking as something that has the ability to legitimize dangerous lies and the power to cause considerable harm was found to overlap with the previously mentioned discourse on fact-checking as an ineffective tool for fighting disinformation.
Discourses of fact-checking 
JD

78,7

\subsection{The agency discourse}

In addition to conceptions about fact-checking itself, multiple ideas on who is responsible and not responsible for conducting it are also found in the analyzed texts. The sub-discourses discussed in this section include representations of ideas about whose performance, or lack thereof, is to blame for inflaming public debate. In this agency discourse, two key subdiscourses were identified. First, fact-checking is constructed as a journalistic responsibility. Second, social media is constructed as a key actor whose (in)ability to conduct fact-checking is perceived to have social consequences.

5.3.1 Fact-checking is a journalistic responsibility that journalists often neglect. The following quote communicates fact-checking as one of the classical components of journalistic work:

Today, through the collaboration Faktiskt, our classical fact-check has been resurrected [...] (SvD23).

It is not clear what the word our actually refers to. It could be either the newspaper SvD, news media and/or journalists in general, but the use of the word suggests that there is a sense of community connected to practicing fact-checking. Although phrasing fact-checking as something that has been resurrected also conveys it as something that was perceived to have been lost, the message conveyed is a hopeful one. It emphasizes fact-checking as a common practice that is intrinsic to the work that journalists do. However, a less hopeful message has also been found to be represented in the texts:

Parallel to the increased potential for spreading disinformation offered by technological developments, investigative journalism is on the decline. Lower profits in the media business are leading to fewer editorial staff and less time for important fact-checking (SvD23).

When discussing fact-checking as a journalistic responsibility, the criticism is usually louder than the praise for journalists. Journalists and news media are often portrayed as being sloppy, and they are frequently reproached for not doing their job correctly.

Swedish media also gladly publishes fake EU news without even fact-checking it. For example, the EU wants to ban porn, snuff, and Christmas soda. Or that the EU sponsors bullfights in Spain. Utter nonsense, all of it! (SvD5)

Often, the fault is perceived to lie with the news organizations rather than with the journalists working for them. Fact-checking is understood as a time-consuming task that is neglected by the news outlets, and the contemporary way of working and the new online media environment is blamed for the lack of journalistic quality.

Speed and penetration have always been rewarded, never laborious toiling over details. There would be nothing wrong with that way of working if it had not impeded the precision of journalism. That is why you constantly find factual inaccuracies in articles on subjects you are familiar with (SvD56).

The problem with fact-checking is often found to lie with those on whose shoulders the responsibility for fact-checking rests. According to this understanding, news media organizations are often perceived as not encouraging work on such details as facts. Instead, news outlets are assumed to prioritize getting the latest story out as soon as possible to maximize profit. This strategy is frequently criticized and is understood to have devastating consequences for the quality of journalism. Although fact-checking, as we have seen, has been criticized for various reasons, no conflicting discourse on the news media wasting too many resources on getting their facts right was found in the texts. However, the problem of insufficient fact-checking is not always understood to be the result of a lack of resources; rather, journalists are thought to be ideologically motivated not to find the truth. 
At this point, it would have been good to have more fact-checking. The [media] hunt went in one direction and the left-wing party has been able to use that hunt in its ideologically motivated campaign against everything that is not publicly monopolized (SvD27).

The author of the opinion piece from which the above quote is taken suggests that journalists did not do their job correctly when reporting on the privatization of schools in Sweden. Instead, they are accused of having joined forces with left-wing politicians to promote a shared agenda.

Recent reports of journalists deliberately inventing stories have triggered discussions on the social consequences of unchecked facts. One example involves the German reporter Claas Relotius at Der Spiegel, who was found to have invented stories about Trump supporters in Fergus Falls, Minnesota and at the US-Mexican border in Arizona. The impact of disinformation produced by journalistic fraud or by journalists' failure to check their own facts is often portrayed as something that risks undermining public trust in the media.

Ester Pollack believes that the situation at the New York Times may increase contempt toward that newspaper in particular and toward journalism in general (DN66).

The situation alluded to in the above quote relates to the New York Times podcast Caliphate, for which a young Canadian citizen had given dubious testimonies about fighting for the Islamic State in Syria. Later, the interviewee was accused of having fabricated his participation in the war and, although the story was retracted by the New York Times, the reporter was heavily criticized for her lack of fact-checking. The article, from which the above quote is taken, contains an interview with a professor of media studies who describes such insufficient fact-checking as a risk that may have a negative impact on public faith in journalism.

5.3.2 Fact-checking should be social media's responsibility. Views about the role that social media plays when it comes to disinformation being spread online are frequently expressed in relation to fact-checking. Generally, social media providers are held accountable for a perceived increase in the spread of disinformation, and it is believed that they are not doing enough to prevent disinformation from impacting public opinion.

[...] new collaborations on fact-checking have started [.. .] But it obviously has not been enough [...]. When it comes to highlighting the content of higher quality [media] rather than fake news, disinformation, and populist campaigns, little progress has been made (DN41).

Although it is generally acknowledged that social media providers are doing more to prevent the spread of disinformation than they used to, they are more often reproached for not doing enough than commended for any improvements that may have taken place. Social media providers are understood to be poorly motivated to do anything about disinformation, an attitude that also extends to their (in)ability to fact-check. The fact-checking that social media giants such as Facebook and Twitter conduct are often described as window dressing in aid of their political interests rather than as a reflection of any genuine wish to fight lies or improve the situation:

All the great giants now declare that they fact-check posts and remove obvious lies. [. . . Social media expert Brit Stakston believes that Facebook had to do something to show that the company was taking the threat of [unduly] influencing the election seriously (SvD61).

The text material reveals that there is a perceived connection between social media's inability or indifference when it comes to supporting a more fact-based environment and declining public trust in news media.

Discourses of fact-checking 
$\mathrm{JD}$

78,7

136
Facebook's infrastructure, on which traditional media has become increasingly dependent, turned out to be the perfect greenhouse for lies. And the media cannot reestablish trust (SvD10).

The relationship between news media and social media is a complex one. The news media is understood to be negatively affected by the amount of unverified information on platforms such as Facebook and Twitter.

Do you remember when Facebook and Twitter were claimed to spell the end of the dictatorships in the world? Instead, it is the social networks that have turned out not to be compatible with democracy [... ] (SvD9).

As indicated in the above quote, Facebook and Twitter were once perceived as advocates of democracy that, not unlike the news media, would promote the public's right to information. Other than being manifested through meta-discursive elaborations on past ways of conceptualizing social media, this understanding of the role of Facebook and Twitter is nowhere to be found in the analyzed texts. Social media providers are described as tech companies with agendas vastly different from the mission of promoting democracy that the news media is perceived to embrace.

\section{Discussion}

This study has explicated the way in which fact-checking is constructed in texts published in two major Swedish newspapers between 2014 and 2020. As fact-checking is discussed increasingly often in news media, it is relevant to investigate how it is discussed. From a discourse-theoretical perspective, these conversations are not only indicative of the way factchecking is talked about but constitutive of how it is practiced. A better understanding of the discursive construction of fact-checking provides insight into social practices pertaining to it and its role in society. Such an understanding is also of particular interest to professionals who conduct fact-checking, e.g. journalists or librarians, and teachers who are engaged in media and information literacy projects in an educational context.

Having identified and discussed multiple discourse formations on fact-checking, it is of course important to point out the fluid nature of the discourses since writing about them makes them appear much more material and tangible than they are.

Three key discourses were identified in the analyzed texts, each comprising multiple subdiscourses and expressing conflicting and contradictory views on fact-checking and the reasons for engaging in it. First, a discourse labeled as "the affirmative discourse" was identified. This discourse was found to contain two sub-discourses that portray factchecking, respectively, as a remedy for disinformation and as a way to establish truth and objectivity. Second, an "adverse discourse" was identified. This discourse was found to be composed of three sub-discourses. The first contests the effectiveness of fact-checking, and the second perceives fact-checking as having the ability to impede democracy. The third subdiscourse portrays fact-checking as something that legitimizes conspiracy theories. Finally, a third discourse labeled "the agency discourse" was identified. It was found to be composed of two sub-discourses with opposing ideas on the roles of actors involved in fact-checking. The first sub-discourse constructs fact-checking as a journalistic responsibility while the second frames social media as a key actor whose (in)ability to perform fact-checking is perceived to have social consequences.

Many of the perspectives found in the analyzed material are consistent with those described in the existing literature. For example, a substantial body of research on the corrective nature of fact-checking argues that the practice of fact-checking makes a difference and contributes to increasing accuracy in public opinion (Amazeen, 2015; Benegal and Scruggs, 2018; Chan et al., 2017; Garrett et al., 2013). This understanding corresponds to the idea of fact-checking as a remedy for disinformation, as found in this study. There are also 
parallels between the understanding of fact-checking as a tool to establish truth and enhance journalistic objectivity expressed in the analyzed material (SvD21; DN28; DN36) and the literature (Amazeen, 2015; Damasceno and Patrício, 2020; York et al., 2020).

Clear parallels to the literature were also found in the critique of fact-checking that was expressed in the adverse discourse. For example, the skepticism that some scholars have expressed toward fact-checking as an effective tool for correcting misrepresentations (Garrett et al., 2013; Nyhan and Reifler, 2014; Sanna et al., 2002) was also found in the analyzed texts. Concerns about fact-checking having the opposite effect to that intended were also raised in both the literature (Nyhan and Reifler, 2010; Sanna et al., 2002) and the analyzed material (DN29; DN58; SvD48). Although the literature on fact-checking refers to the same conflicting ideas about core journalistic principles and journalists' relationship to truth, some scholars have challenged the idea of fact-checking as a tool for establishing truth (Uscinski, 2015; Uscinski and Butler, 2013).

In contrast, moral concerns relating to the fact-checking of obvious lies about, for example, the Holocaust identified in the present analysis (DN35; DN36) could not be discerned to have parallels in the literature. Although ideas about fact-checking as a genuinely journalistic responsibility were found in the analyzed texts (DN66; SvD23; SvD27) and the literature (Amazeen, 2015; Graves, 2016, 2018; Graves et al., 2016; Mena, 2019), the literature tends to be much more optimistic about journalists' ability to perform fact-checking (Amazeen, 2015, 2020; Graves, 2016, 2018; Graves and Anderson, 2020; Mena, 2019). In the analyzed material, journalists are more often the target of substantial criticism for their fact-checking performance, and there was a much greater emphasis on social media providers' responsibility to engage in fact-checking.

Finally, the analyzed material was not found to make the same clear distinction found in the literature between the fact-checking of, for example, public statements and journalists' ability to fact-check their own texts. The literature on contemporary fact-checking discusses the practice of checking political statements, viral hoaxes or other types of public messages that the fact-checkers themselves have not produced. This practice is clearly distinguished from the practice of newspapers engaging in checking their own reports before they go to print (Allern and Pollack, 2019). The analyzed corpus of texts was found to blend ideas about journalists being inept at conducting fact-checking of external information with views on their inability to report correctly. The two different "brands" of fact-checking are often conceptualized in the analyzed material as interconnected, and journalists are often portrayed as being incapable of taking on the task of fact-checking when they cannot even get their own facts straight.

Although the conflicting discourses identified in the analysis have parallels to ones identified in previous research, the analyzed corpus of texts portrays fact-checking as being a much more multifaceted and politicized practice than previous portrayals have shown.

\subsection{Limitations}

Contemporary fact-checking has emerged as a global media genre (Juneström, 2020), and practices for fact-checking are influenced by international organizations such as the Poynter Institute for Media Studies, which launched the International Fact-Checking Network (IFCN) in 2015. However, on the basis of this study set in a Swedish news media context, it is not possible to make any direct inference about the presence of the same discourses in a global setting. Nevertheless, it is conceivable that such themes and concerns are not unique to Sweden. To verify whether the findings are applicable outside Sweden, further studies would be required. It would indeed be interesting to compare these results with those of similar studies conducted in, for example, the USA. For further insight into how fact-checking is discussed and talked about, it would also be relevant to extend the study to include social
Discourses of fact-checking 
$\mathrm{JD}$

78,7

media. Social media forums, e.g. on Facebook, that are devoted to discussing the topics of factchecking and media literacy would make productive settings for such investigations.

\section{References}

Alexander, S. and Wood, L.M. (2019), "No news is good news? Satirical news videos in the information literacy classroom", Portal: Libraries and the Academy, Johns Hopkins University Press, Baltimore, Vol. 19 No. 2, pp. 253-278.

Allern, S. and Pollack, E. (2019), Källkritik!: journalistik i lögnens tid, 1st ed., Studentlitteratur, Lund.

Amazeen, M.A. (2015), "Revisiting the epistemology of fact-checking", Critical Review, Vol. 27 No. 1, pp. 1-22.

Amazeen, M.A. (2019), "Practitioner perceptions: critical junctures and the global emergence and challenges of fact-checking", International Communication Gazette, Vol. 81 Nos 6-8, pp. 541-561.

Amazeen, M.A. (2020), "Journalistic interventions: the structural factors affecting the global emergence of fact-checking", Journalism, Vol. 21 No. 1, pp. 95-111.

Benegal, S.D. and Scruggs, L.A. (2018), "Correcting misinformation about climate change: the impact of partisanship in an experimental setting”, Climatic Change, Vol. 148 Nos 1-2, pp. 61-80.

Brandtzaeg, P.B. and Følstad, A. (2017), "Trust and distrust in online fact-checking services", Communications of the ACM, Association for Computing Machinery, Vol. 60 No. 9, pp. 65-71.

Brandtzaeg, P.B., Følstad, A. and Chaparro Domínguez, M.Á. (2018), "How journalists and social media users perceive online fact-checking and verification services", Journalism Practice, Vol. 12 No. 9, pp. 1109-1129.

Chan, M.S., Jones, C.R., Hall Jamieson, K. and Albarracín, D. (2017), "Debunking: a meta-analysis of the psychological efficacy of messages countering misinformation", Psychological Science, Vol. 28 No. 11, pp. 1531-1546.

Damasceno, D.D.R. and Patrício, E. (2020), "Journalism and fact-checking: typification of sources used for checking and criteria for selecting fact-checked material - an analysis by Agência Lupa and Aos Fatos”, Brazilian Journalism Research, Vol. 16 No. 2, pp. 368-393.

Fairclough, N. (1992), Discourse and Social Change, Polity, Cambridge.

Fairclough, N. (2010), Critical Discourse Analysis: The Critical Study of Language, 2nd ed., Longman, Harlow.

Fallis, D. (2015), "What is disinformation?", Library Trends, Johns Hopkins University Press, Baltimore, Vol. 63 No. 3, pp. 401-426.

Farkas, J. and Schou, J. (2020), Post-Truth, Fake News and Democracy. Mapping the Politics of Falsehood, Routledge, New York.

Garrett, R.K., Nisbet, E.C. and Lynch, E.K. (2013), "Undermining the corrective effects of media-based political fact checking? The role of contextual cues and naïve theory: undermining corrective effects", Journal of Communication, Vol. 63 No. 4, pp. 617-637.

Gibson, C. and Jacobson, T.E. (2018), "Habits of mind in an uncertain information world", Reference and User Services Quarterly, American Library Association, Chicago, Vol. 57 No. 3, pp. 183-192.

Graves, L. (2016), Deciding What's True. The Rise of Political Fact-Checking in American Journalism, Columbia University Press, New York.

Graves, L. (2018), "Boundaries Not Drawn: mapping the institutional roots of the global fact-checking movement", Journalism Studies, Vol. 19 No. 5, pp. 613-631.

Graves, L. and Anderson, C. (2020), "Discipline and promote: building infrastructure and managing algorithms in a 'structured journalism' project by professional fact-checking groups", New Media and Society, Vol. 22 No. 2, pp. 342-360.

Graves, L., Nyhan, B. and Reifler, J. (2016), "Understanding innovations in journalistic practice: a field experiment examining motivations for fact-checking: understanding innovations in journalistic practice", Journal of Communication, Vol. 66 No. 1, pp. 102-138. 
Huvila, I. (2012), Information Services and Digital Literacy: In Search of the Boundaries of Knowing, Chandos Publishing, Oxford.

Iosifidis, P. and Nicoli, N. (2020), Digital Democracy, Social Media and Disinformation, Routledge, London, doi: 10.4324/9780429318481.

Ireland, S. (2018), "Fake news alerts: teaching news literacy skills in a meme world", The Reference Librarian, Vol. 59 No. 3, pp. 122-128.

Jacobson, T. and Mackey, T. (2013), "Proposing a metaliteracy model to redefine information literacy", Communications in Information Literacy, Vol. 7 No. 2, doi: 10.15760/comminfolit.2013.7.2.138.

Jones-Jang, S.M., Mortensen, T. and Liu, J. (2021), "Does media literacy help identification of fake news? Information literacy helps, but other literacies don't", American Behavioral Scientist, SAGE Publications, Vol. 65 No. 2, pp. 371-388.

Juneström, A. (2020), “An emerging genre of contemporary fact-checking”, Journal of Documentation, Emerald Publishing, Vol. 77 No. 2, pp. 501-517.

LaPierre, S.S. and Kitzie, V. (2019), "Lots of questions about 'fake news": how public libraries have addressed media literacy, 2016-2018”, Public Library Quarterly, Vol. 38 No. 4, pp. 428-452.

Lorenz, R., Endberg, M. and Bos, W. (2019), "Predictors of fostering students' computer and information literacy - analysis based on a representative sample of secondary school teachers in Germany", Education and Information Technologies, Vol. 24 No. 1, pp. 911-928.

Marietta, M., Barker, D.C. and Bowser, T. (2015), "Fact-checking polarized politics: does the fact-check industry provide consistent guidance on disputed realities?", The Forum, De Gruyter, Vol. 13 No. 4, pp. 577-596.

Mena, P. (2019), "Principles and boundaries of fact-checking: journalists' perceptions", Journalism Practice, Vol. 13 No. 6, pp. 657-672.

Mindich, D.T.Z. (1998), Just the Facts: How Objectivity Came to Define American Journalism, New York University Press, New York.

Nieminen, S. and Rapeli, L. (2019), "Fighting misperceptions and doubting journalists' objectivity: a review of fact-checking literature", Political Studies Review, Vol. 17 No. 3, pp. 296-309.

Nyhan, B. and Reifler, J. (2010), "When corrections fail: the persistence of political misperceptions", Political Behavior, Vol. 32 No. 2, pp. 303-330.

Nyhan, B. and Reifler, J. (2014), "The effect of fact-checking on elites: a field experiment on US State legislators", American Journal of Political Science, Vol. 59 No. 3, pp. 628-640.

Rubin, V.L. (2019), "Disinformation and misinformation triangle: a conceptual model for 'fake news' epidemic, causal factors and interventions", Journal of Documentation, Vol. 75 No. 5, pp. 1013-1034.

Sanna, L.J., Schwarz, N. and Stocker, S.L. (2002), "When debiasing backfires: accessible content and accessibility experiences in debiasing hindsight", Journal of Experimental Psychology: Learning, Memory, and Cognition, Vol. 28 No. 3, pp. 497-502.

Søe, S.O. (2017), "Algorithmic detection of misinformation and disinformation: gricean perspectives", Journal of Documentation, Emerald Publishing, Vol. 74 No. 2, pp. 309-332.

Søe, S.O. (2021), "A unified account of information, misinformation, and disinformation", Synthese, Vol. 198 No. 6, pp. 5929-5949.

Stamps, D. (2020), "Media literacy as liberator: black audiences' adoption of media literacy, news media consumption, and perceptions of self and group members", Journal of International and Intercultural Communication, pp. 1-18.

Tamboer, S.L., Kleemans, M. and Daalmans, S. (2020), “We are a neeeew generation': early adolescents' views on news and news literacy", Journalism, May, doi: 10.1177/ 1464884920924527.

Uscinski, J.E. (2015), “The epistemology of fact checking (is still naive): rejoinder to amazeen”, Critical Review, Vol. 27 No. 2, pp. 243-252.

Discourses of fact-checking 
$\mathrm{JD}$

78,7

Uscinski, J.E. and Butler, R.W. (2013), “The epistemology of fact checking”, Critical Review, Vol. 25 No. 2, pp. 162-180.

York, C., Ponder, J.D., Humphries, Z., Goodall, C., Beam, M. and Winters, C. (2020), "Effects of factchecking political misinformation on perceptual accuracy and epistemic political efficacy", Journalism and Mass Communication Quarterly, Vol. 97 No. 4, pp. 958-980.

\section{Corresponding author}

Amalia Juneström can be contacted at: amalia.junestrom@abm.uu.se

For instructions on how to order reprints of this article, please visit our website: www.emeraldgrouppublishing.com/licensing/reprints.htm Or contact us for further details: permissions@emeraldinsight.com 